\title{
Cutting performance of TiCN-HSS cermet in dry machining
}

\author{
J.A. Canteli ${ }^{a}$, J.L. Cantero ${ }^{\text {a }}$, N.C. Marín ${ }^{\mathrm{a}}$, B. Gómez ${ }^{\mathrm{b}}$, E. Gordo ${ }^{\mathrm{b}}$, M.H. Miguélez ${ }^{\mathrm{a}, *}$ \\ a Department of Mechanical Engineering, Universidad Carlos III, Avda. Universidad 30, Leganés 28911, Madrid, Spain \\ ${ }^{\mathrm{b}}$ Department of Materials Science, Universidad Carlos III de Madrid, Avda. Universidad 30, Leganés 28911, Madrid, Spain
}

Keywords:

New cutting material

Cermets

HSS-TiCN

Wear
This work is focused on the cutting performance of a new cermet based on high-speed steel (HSS) matrix with hard phase TiCN. The processing route to manufacture the cermet M2 +50 vol.\% TiCN is described. Orthogonal cutting tests, carried out in a lathe showed the ability of the new cermet to achieve turning operations, showing reasonably wear resistance performing dry cutting operations. Tool life was significantly increased, when the cermet was compared with the reference material M2 without reinforcement and with commercial HSS M2. Evolution of flank wear and chipping wear, being the dominant wear patterns, were analysed.

\section{Introduction}

High-speed steels, cemented carbides and cermets are the most widely used materials for cutting and forming applications. Among them, the importance of titanium carbonitride ( $\mathrm{TiCN}$ ) based cermets, has increased in the last decades as they present superior cutting performance than conventional cemented carbides (Ettmayer et al., 1995). TiCN-based cermets exhibit an excellent combination of high temperature hardness, strength, wear resistance, thermal conductivity and chemical stability, and they have been used for semifinishing and finishing operations on steel and cast iron (Zhang et al., 2007; Bellosi et al., 2003). This type of cermets is constituted by TiCN particles dispersed in a metal matrix, normally made of $\mathrm{Ni}$, Co or their mixtures. Some metal carbides (e.g. WC, NbC, Mo2C, TaC) are normally added to improve not only the performance but also the processing, by improving the wettability between the ceramic and the liquid phase, as well as enhance density and decrease particle growth rate (Li et al., 2008; Rahimi et al., 2007). Those additions are necessary to overcome the poorer processing of $\mathrm{TiCN}$ cermets with respect to the cemented carbides, which is one of their disadvantages, others being lower toughness and poorer thermal shock resistance.

The use of iron as the matrix of cermets has been studied (Aigner et al., 1997) because of its advantages over Co or Ni. These include non-toxicity, abundance of resources leading to lower cost, and the ability to be hardened by heat treatment, which could lead to high hardness with lower quantity of ceramic phase (Gordo et al., 2008).

\footnotetext{
* Corresponding author. Tel.: +34 9162494 02; fax: +34 916249430 .
} E-mail address: mhmiguel@ing.uc3m.es (M.H. Miguélez).
Fe-based cermets also present low sintering performance due to poor wettability of the liquid phase, the risk of producing reaction products with the reinforcement that lead to embitterment (Umanskii, 2001), and the risk of agglomeration of the ceramic particles that do not permit a homogeneous dispersion of hard phase into the matrix (Gordo et al., 2000). The addition of $\mathrm{Cr}$ to Fe can improve the wettability, as it lowers the contact angle close to $0^{\circ}$, thus wetting the surface of TiCN with the alloy (Umanskii, 2001). As elements like W, Mo and their carbides have also been reported to improve sintering behaviour of TiCN cermets, a high-speed steel (grade M2) has been chosen as matrix of a new Fe-based composite reinforced with TiCN particles. The M2 is one of the most widely employed high-speed steels, whose sintering behaviour and heat treatment response are well known (Davis, 1995), but changes are expected when ceramic particles are added. Previous works have studied the processing of this composite (M2-TiCN) from the mixing of powders (Gómez et al., 2006) to their sintering behaviour (Gomez and Gordo, 2007), and have compared the results with a plain Fe matrix composite (Fe-TiCN). The response to heat treatment (Gordo et al., 2008) and the oxidation and wear behaviour (Gómez et al., 2009) has also been analysed.

First works about development of cermets based in an iron matrix for cutting tools were published two decades ago (Deo et al., 1988; Deshpande et al., 1992). Cemented carbide with iron based binder showed high toughness and good results when performing turning tests, allowing to machine with increased cutting speed when compared with high speed steel without reinforcement (Deshpande et al., 1997). Although promising preliminary results were observed, the development of this type of cermets has not been continued, as far as the bibliographic review was developed. 
On the other hand the reinforcement of high-speed steel with hard materials has been implemented in commercial cutting tools. As an example, HSS reinforced with $35-60 \%$ of TiN has been used in some milling tools for grooving operations (Sandvik Coromant, 2003), with the objective to combine wear resistance with toughness.

Summarizing, cermets bonded with iron-based matrix have not been widely used in cutting tools. However, preliminary results obtained in cutting tests and the advantages of the use of iron described previously, could lead to consider this type of cermet as a cutting material with intermediate properties between HSS and cemented carbide.

The aim of this work is to show the ability of the new cermet ( $\mathrm{M} 2+50$ vol.\% TiCN) to achieve improved cutting operations when compared to the reference material, M2 without reinforcement, and also with a commercial HSS M2.

Concerning the material development, this work is focused in the results of heat treatment which permitted the selection of the optimal processing parameters to manufacture the inserts.

Orthogonal cutting tests were performed for reference material M2, commercial HSS and the cermet M2+50 vol.\% TiCN. Tool life was greatly increased with the addition of hard phase. Tool wear mechanisms and evolution were analysed for the cermet and the reference $M 2$, being significantly improved for the former material.

\section{Materials and experimental procedure}

\subsection{Materials development}

The composite material studied (M2-TiCN) was constituted by a high-speed steel matrix (M2 grade, containing 6\%W, $5 \% \mathrm{Mo}, 4 \% \mathrm{Cr}$, $2 \% \mathrm{~V}, 0.85 \% \mathrm{C}$ ) and $50 \mathrm{vol} . \%$ of TiCN particles, and was prepared by the conventional powder metallurgy (PM) route of mixing of starting powders, pressing and sintering. The M2 powder was selected for the particle size, which although bigger than the TiCN particles, permits to avoid the need of high-energy milling techniques for blending. The same powder was used for manufacturing M2 reference samples. The TiCN powder was selected with the molar composition $0.5 \mathrm{C}-0.5 \mathrm{~N}$, that has been reported to be the most beneficial for hardness, bending strength (Zhang et al., 2006) and oxidation resistance (Pastor, 1988). The characteristics of starting powders are given in Table 1.

Powders of M2 and TiCN were dry mixed for $4 \mathrm{~h}$ and then compacted in a uniaxial press at $1000 \mathrm{MPa}$ to obtain cylinders of $16 \mathrm{~mm}$ diameter and $4 \mathrm{~mm}$ height. The green compacts were sintered in vacuum $\left(10^{-5} \mathrm{mbar}\right)$ at $1450{ }^{\circ} \mathrm{C}$ for $60 \mathrm{~min}$. The conditions of sintering were determined in previous work (Gómez, 2007). Likewise, powders of M2 were pressed at $700 \mathrm{MPa}$ into cylinders, and sintered in vacuum, but at lower sintering temperature $\left(1250^{\circ} \mathrm{C}\right)$ and time (30 min). Some characteristics of as-sintered materials are listed in Table 2 and the microstructures are shown in Fig. 1.

The microstructure of the as-sintered M2 steel, constituted by a ferritic matrix and carbides, is shown in Fig. 1a. In the as-sintered condition the brighter carbides were typically $\mathrm{M}_{6} \mathrm{C}$, where $\mathrm{M}$ is $\mathrm{W}$, $\mathrm{Mo}$ and $\mathrm{Fe}$, whereas the grey-contrast phase corresponded to V-rich MC carbides. The M2 + TiCN composite can be seen in Fig. $1 \mathrm{~b}$; being constituted by a ferritic steel matrix (grey contrast), TiCN particles (black contrast) and carbides from the alloying elements of the M2 steel (bright contrast). These phases can be seen in more detail in Fig. 2, where it is clearer that bright carbides were surrounding the TiCN particles, acting as an interphase. There was no any other type of reaction between matrix and reinforcement, as it is usual for other cermets.

The sintered materials were submitted to heat treatments consisting of quenching from different austenitizing temperatures and double tempering. The heating to austenite was done in a muffle type furnace under protecting $\mathrm{Ar}$ atmosphere and the conditions of treatment were adjusted for each material as follows. For the M2 steel, taken as reference, two austenitizing temperatures were used, $1150^{\circ} \mathrm{C}$ and $1200^{\circ} \mathrm{C}$, based on usual treatments for this steel (Hoyle, 1988). The austenitizing temperatures for the composite $\mathrm{M} 2-\mathrm{TiCN}$ were also $1150^{\circ} \mathrm{C}, 1200^{\circ} \mathrm{C}$ adding $1250^{\circ} \mathrm{C}$ with the idea to promote a higher dissolution of the ceramic phase. In both cases, the quenching media was oil and the double tempering was done at two temperatures: $540^{\circ} \mathrm{C}$ and $560^{\circ} \mathrm{C}$. Both the austenitizing and tempering times were fixed to $60 \mathrm{~min}$.

After the heat treatments all the materials were characterized mechanically by measuring hardness (HV30), bending strength (three point bending test) and fracture toughness (by indentation methods). The microstructure of heat-treated materials was also analysed by means of scanning electron microscopy (SEM), microanalysis by EDX, and image analysis.

\subsection{Orthogonal cutting tests}

Orthogonal cutting tests were carried out in a Pinacho CNC lathe (mod. Smart-turn 6/165) equipped with a tool holder and force measuring device, shown in Fig. 3a and b.

In a first stage tool materials developed in the laboratory, both $\mathrm{M} 2$ and $\mathrm{M} 2+50 \% \mathrm{TiCN}$, were tested at constant cutting speed and feed rate $(30 \mathrm{~m} / \mathrm{min}$ and $0.1 \mathrm{~mm} / \mathrm{rev}$, respectively). In the second stage, the influence of cutting speed in the range $30-60 \mathrm{~m} / \mathrm{min}$ was analysed for the new cermet and also for commercial HSS inserts. All inserts were manufactured by electro discharge machining (EDM). The inserts made from commercial HSS M2 were generated from a commercial drill by EDM (according to standard DIN $338 \mathrm{~N}$, see Guhring Ltd., http://www.guhring.co.uk/) in order to obtain the same tool geometry as the M2 and M2+50\% TiCN. The aim of the tests was not only to show the ability of the new material to be used in cutting inserts. Also the suitability of the manufacture process was checked comparing the cutting performance of the M2 manufactured in the lab and commercial M2.

Since the new cermet and the reference material M2 were developed in the laboratory, a limited number of inserts were manufactured. The characteristics of the manufacturing process

Table 1

Characteristics of starting powders.

\begin{tabular}{|c|c|c|c|c|c|}
\hline Powder & Composition (wt.\%) & Particle size $(\mu \mathrm{m})$ & Density $\left(\mathrm{g} / \mathrm{cm}^{3}\right)$ & Morphology & Supplier \\
\hline M2 & $6 \% \mathrm{~W}, 5 \% \mathrm{Mo}, 4 \% \mathrm{Cr}, 2 \% \mathrm{~V}, 0.85 \% \mathrm{C}$, Fe bal. & $<22$ & 8.16 & Spherical & Osprey \\
\hline $\mathrm{TiCN}$ & $11.1 \%$ N, $10 \%$ C, Ti bal. & $D_{50}=7.5$ & 5.08 & Irregular & H.C. Starck \\
\hline
\end{tabular}

Table 2

Characteristics of sintered materials.

\begin{tabular}{|c|c|c|c|}
\hline Material & Phases at the microstructure & Density $\left(\mathrm{g} / \mathrm{cm}^{3}\right) /(\%$ theoretical $)$ & Hardness HV30 \\
\hline M2 & Ferritic matrix, Vc carbides $(\mathrm{W}, \mathrm{Mo}, \mathrm{Fe})_{6} \mathrm{C}$ carbides & $7.79 / 95 \%$ & $620 \pm 30$ \\
\hline M2-TiCN & TiCN particles, Fe matrix, carbides & $6.53 / 99 \%$ & $1250 \pm 50$ \\
\hline
\end{tabular}



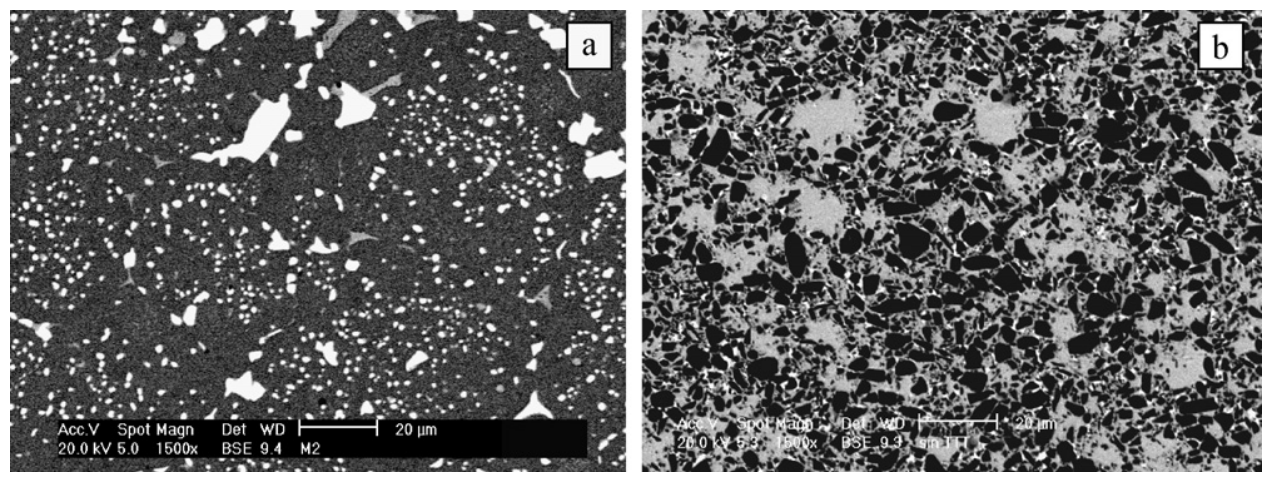

Fig. 1. Microstructures of the as-sintered materials: (a) base material M2; (b) M2 + TiCN composite.

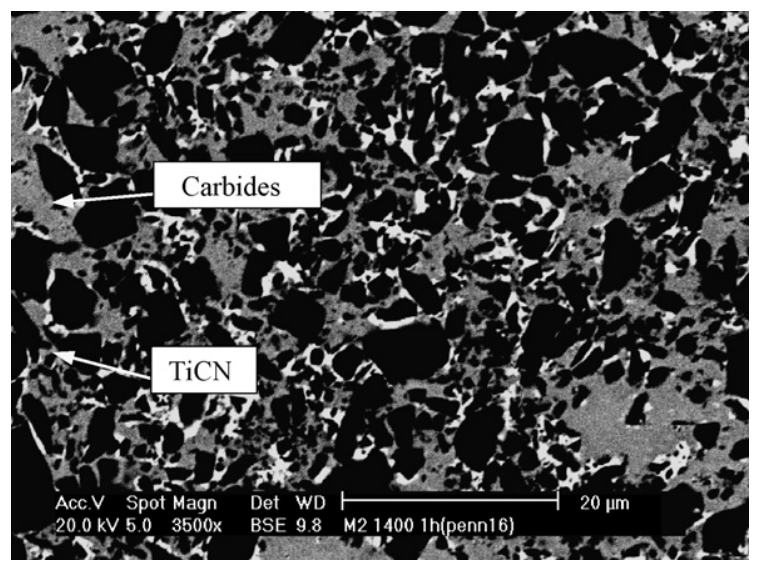

Fig. 2. Detail of the microstructure of M2 + TiCN composite.

allowed to obtaining specimens with good mechanical properties, as was described previously. In order to prevent variability in the inserts, turning tests were repeated to obtain wear evolution of the inserts.

The workpiece material was a cold rolled tube of steel St 35, DIN 2391 ( $C<0.17 \%, \mathrm{Si}<0.35 \%, \mathrm{Mn}<0.4 \%, \mathrm{P}<0.025 \%, \mathrm{~S}<0.025 \%$, with an external diameter of $25 \mathrm{~mm}$ and thickness equal to $2 \mathrm{~mm}$ (depth of cut was $2 \mathrm{~mm}$ ). Air cooling was used during dry cutting tests.
Rake angle is one of the most influencing parameters in the tool behaviour. In general increased rake angle is related with a decrease in cutting force and temperature together with a weakened cutting edge. The analysis of the performance of the new cutting material included the study of two different rake angles. The insert was positioned in the support designed to obtain variable rake angle $\left(0^{\circ}\right.$ and $10^{\circ}$, see Fig. $\left.4 \mathrm{a}\right)$. Clearance surface was machined by electro discharge machining (EDM). Sharp cutting edge was generated, cutting edge angle was respectively $85^{\circ}$ and $75^{\circ}$, corresponding to rake angle $0^{\circ}$ and $10^{\circ}$. Clearance angle was $5^{\circ}$ in all cases. This tool holder was instrumented with strain gages allowing on-line monitoring of cutting force during orthogonal cutting of the workpiece (see Fig. 4b). Cutting edge of the insert is coaxial with the axe of the support, avoiding the effect of torque during cutting.

After each test, worn surfaces of the cutting tools were studied with optical microscopy and SEM techniques.

\section{Experimental results}

\subsection{Heat treatment}

Fig. 5a shows the variation of hardness with respect to the material in the as-sintered condition (that presented a value of 1250 HV30) for the different steps of heat treatment. From these curves, the following observations can be made: (a)

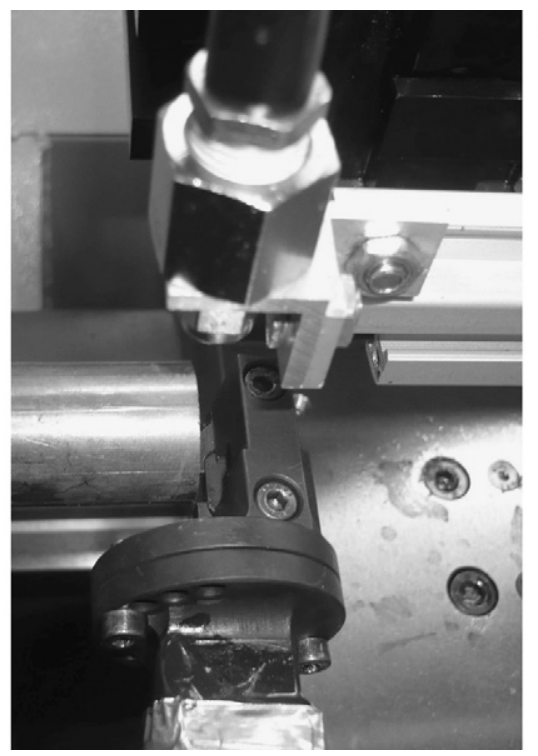

(b)

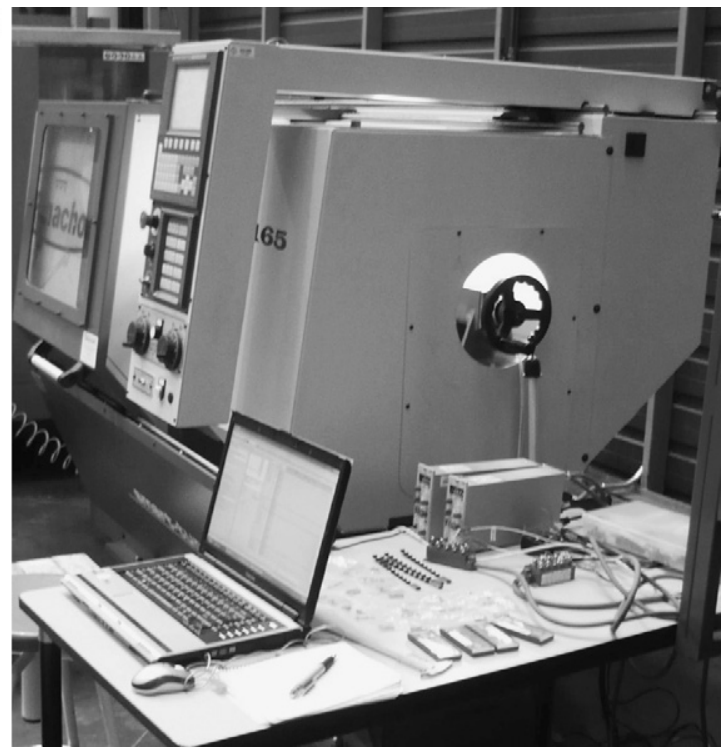

Fig. 3. (a) Tool holder and air cooling device in the lathe. (b) Data acquisition system in the lathe. 


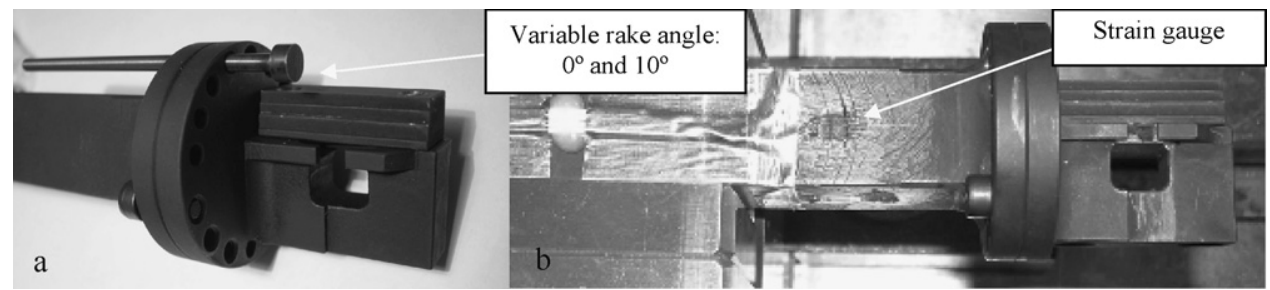

Fig. 4. (a) Detail of insert support for tool positioning in the lathe. (b) Insert holder instrumented to measure cutting forces.

- The hardness of the composite after quenching was higher than the as-sintered material, as it was expected.

- When the austenitizing temperature increases, the hardness after quenching decreased.

- For the two lowest austenitizing temperatures $\left(1150^{\circ} \mathrm{C}\right.$ and $1200^{\circ} \mathrm{C}$ ), the hardness after the 2 nd tempering was higher than after the 1st tempering, as it was expected for a HSS. However, when the austenization is at $1250^{\circ} \mathrm{C}$, the hardness decreased after tempering.

Fig. $5 \mathrm{~b}$ shows the variation of fracture toughness with respect to the material in the as-sintered condition for the different steps of heat treatment.

As a result of the study concerning heat treatments, the conditions of treatment selected for the materials to be submitted to cutting experiments were quenching in oil at $1200^{\circ} \mathrm{C}$ and double tempering at $560^{\circ} \mathrm{C}$ for both the composite $\mathrm{M} 2+\mathrm{TiCN}$ and the $\mathrm{M} 2$ as reference material.

The final hardness of the composite after quenching at $1200^{\circ} \mathrm{C}$ and double tempering at $560^{\circ} \mathrm{C}$ was $25 \%$ higher than the as-sintered
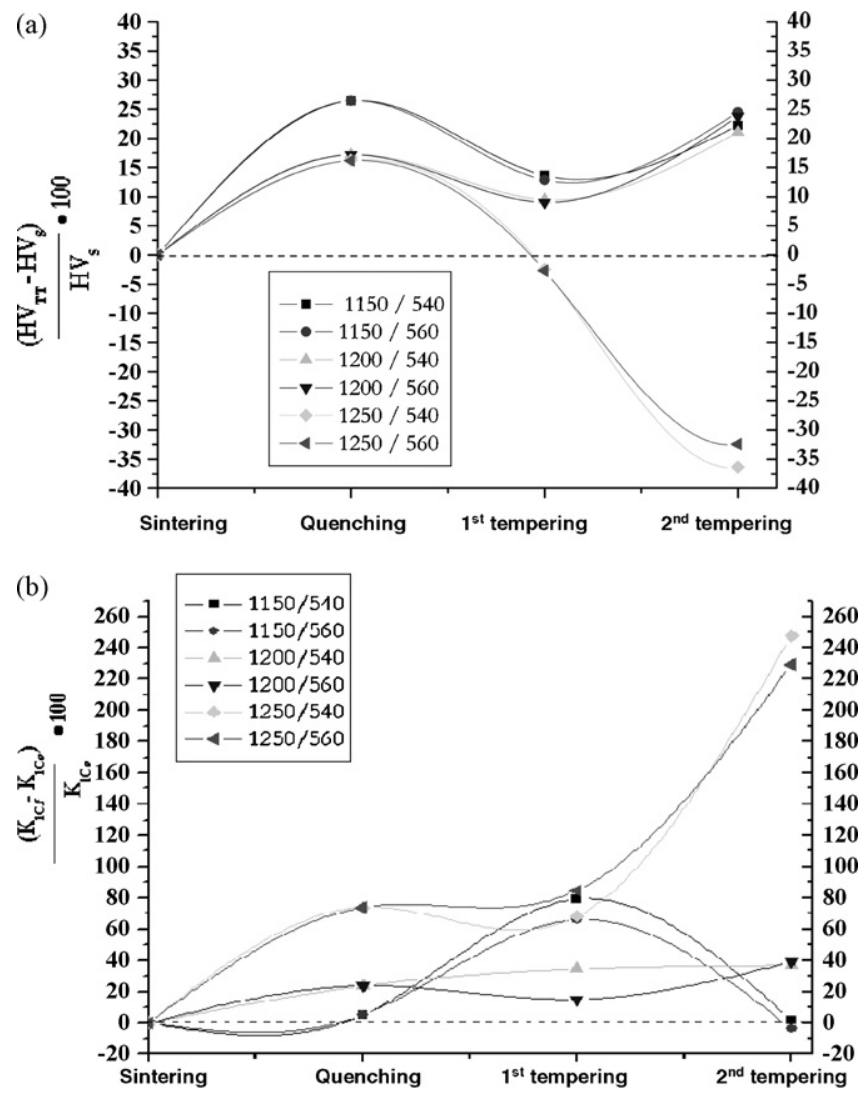

Fig. 5. (a) Variation of hardness and (b) fracture toughness, with heat treatment for M2-TiCN composite, related to the hardness of the as-sintered material (1250 HV30). material, reaching values of 1550 HV30; the fracture toughness for the same conditions of treatment increases the $40 \%$ with respect to the as-sintered material, up to $14 \mathrm{MPa} \mathrm{m}^{1 / 2}$.

\subsection{Flank wear evolution}

The $\mathrm{M} 2$ and $\mathrm{M} 2+50 \% \mathrm{TiCN}$ cermet discs were machined with electro-discharge machining (EDM) to get the desired insert geometry, see Fig. 6.

As was described previously, each test was carried out twice showing good repeatability. Numerical data presented in this section are the mean of both tests.

Cutting forces were measured during turning tests of new cermet. Wear evolution was analysed for the reference material M2 and the cermet. Analysis of worn tools showed two dominant wear patterns, flank and chipping wear, for both M2 and M2+50\%TiCN. Tool life was considered to be expended when the flank wear reached $0.5 \mathrm{~mm}$.

\subsubsection{Tool material M2 sintered in laboratory}

Optical images analysis was applied to determine the evolution of flank wear with cutting time. Tool life achieved using the tool with rake angle $0^{\circ}$ was $5 \mathrm{~min}$ (after cutting time equal to $5 \mathrm{~min}$, tool flank wear was $0.5 \mathrm{~mm}$ ). When tool rake angle was increased to $10^{\circ}$, tool life decreased to $2.5 \mathrm{~min}$.

Evolution of flank wear with cutting time is shown in Fig. 7a. Tool flank wear for the $\mathrm{M} 2$ tool, rake angle $0^{\circ}$, in cutting time $5 \mathrm{~min}$ corresponding to expended tool life is presented in Fig. 7b.

Small cracks, from 0.05 to $0.15 \mathrm{~mm}$ width, located in the cutting edge were observed in the M2 tools. These cracks firstly appeared in several points located in the cutting edge and extended along the cutting edge as cutting time increased. The sharp cutting edge of the tools promoted the chipping phenomenon. Due to the presence of these cracks, temperature increased in cutting zone accelerating the evolution of wear. When the rake angle was $0^{\circ}$, the resistance of the cutting edge to chipping wear was improved because of the more robust geometry than that obtained with rake angle $10^{\circ}$. This could be one of the reasons of the improvement of tool life observed in the former case.

SEM (scanning electron microscopy) image of the cutting edge obtained with a microscope Philips XL-30 is shown in Fig. 8. The image corresponds with a cutting tool with rake angle $10^{\circ}$ at the end of life.

The end of life for the cutting tool with rake angle $10^{\circ}$ corresponds to diminished cutting time $(2.5 \mathrm{~min})$. The cracks for this

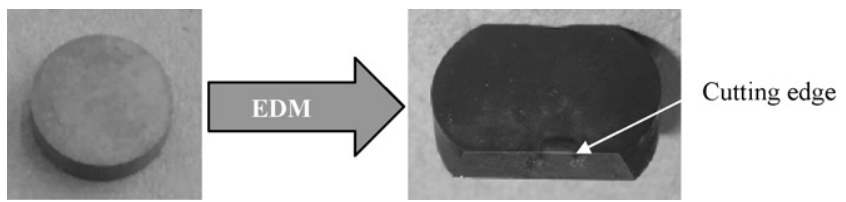

Fig. 6. Sintered specimen (left) and cutting insert with cutting edge generated by EDM. 
(a)

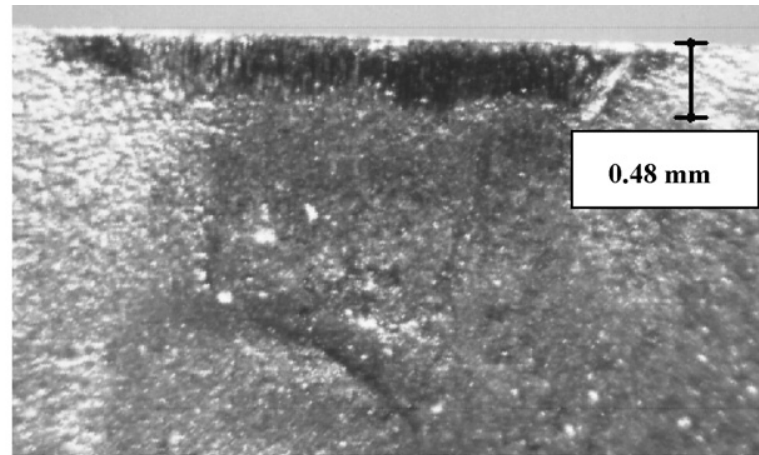

(b)

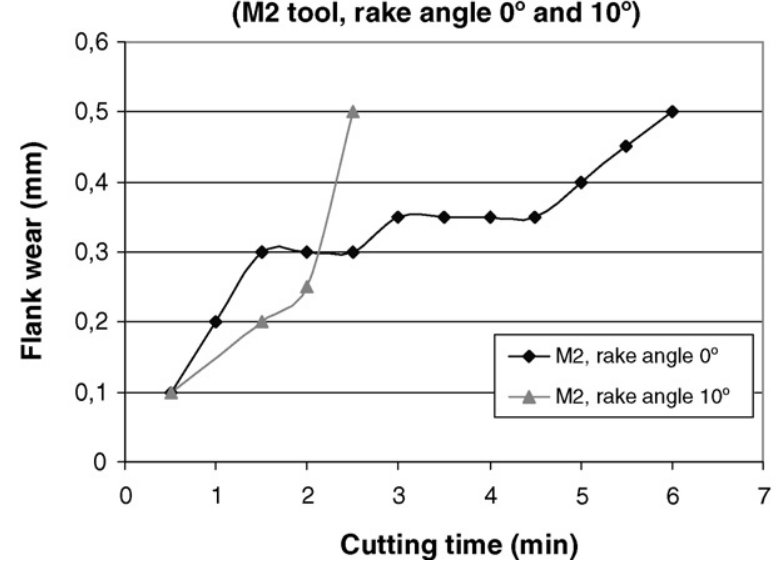

Fig. 7. M2 tool material. (a) Flank wear measured during the experimental study of wear evolution, cutting insert with rake angle equal to $0^{\circ}$. (b) Effect of rake angle in flank wear evolution. tool were located in wider zones of the cutting edge (Fig. 8a) than cracks observed in the case of tool with rake angle $0^{\circ}$. This behaviour is related with the more robust geometry of the tool with rake angle $0^{\circ}$ that more resistant to crack progression during cutting.

It is possible to observe also the flank wear in the clearance surface. Cracks appear due to brittle micro-failure of the material. The analysis EDS (energy dispersive X-ray) revealed adhesion of the workpiece material in an extended zone in clearance surface (the light zone in the Fig. 8b).

\subsubsection{Tool material $\mathrm{M} 2+50 \% \mathrm{TiCN}$}

The cermet tool with rake angle $0^{\circ}$ presented a tool life equal to $85 \mathrm{~min}$. The same tool material with rake angle $10^{\circ}$, presented a tool life of $54 \mathrm{~min}$.

These are important results, showing a significant increase of tool life when the reference material (high speed steel M2) was reinforced with the hard phase.

The effect of rake angle in cutting and thrust force is showed in Fig. 9a and b.

It was observed an increase of cutting and thrust force with cutting time, when a rake angle of $10^{\circ}$ was considered. This effect was less accused for the tool with rake angle $0^{\circ}$.

Fig. 10a shows an example of flank wear for tool M2-50\%TiCN during the process of wear analysis of inserts with rake angle $0^{\circ}$. Flank wear evolution is presented in Fig. 10b, for a tool M2+50\% TiCN. The tool with rake angle $0^{\circ}$ showed slower wear evolution. Flank wear was considerably decreased with the addition of the hard phase, as can be deduced from the comparison between Figs. 10 and 7.

SEM image of the cutting edge is shown in Fig. 11. Small cracks located in the cutting edge were also observed in the reinforced tool. The image corresponds with cutting inserts $\mathrm{M} 2+50 \% \mathrm{TiCN}$ with rake angle $10^{\circ}$ at the end of life. Since tool life is large, the cracks due to the brittle fracture of the material were extended all
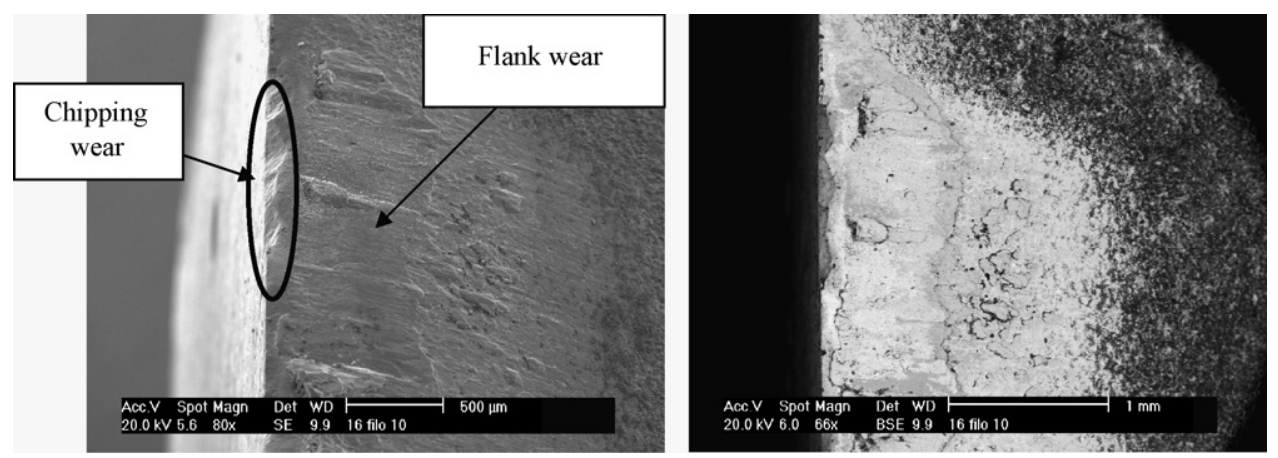

Fig. 8. Tool M2 rake angle $10^{\circ}$, end of tool life: (a) image showing cutting edge and clearance and rake surface. (b) SEM image of clearance surface.
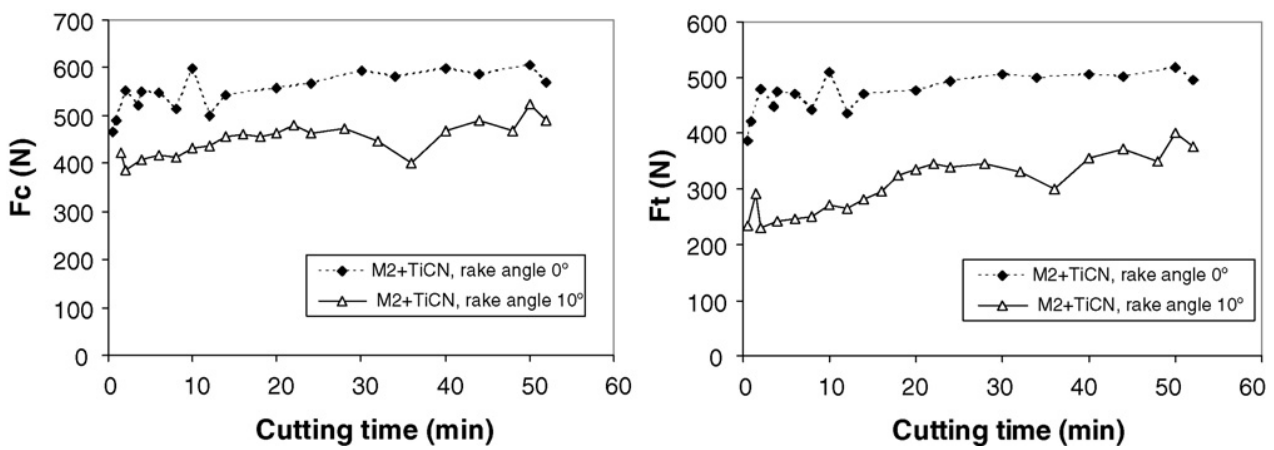

Fig. 9. Cutting force $(\mathrm{Fc})$ and thrust force $(\mathrm{Ft})$ components evolution vs cutting time (tool material $\mathrm{M} 2+50 \% \mathrm{TiCN}$ ). 
(a)

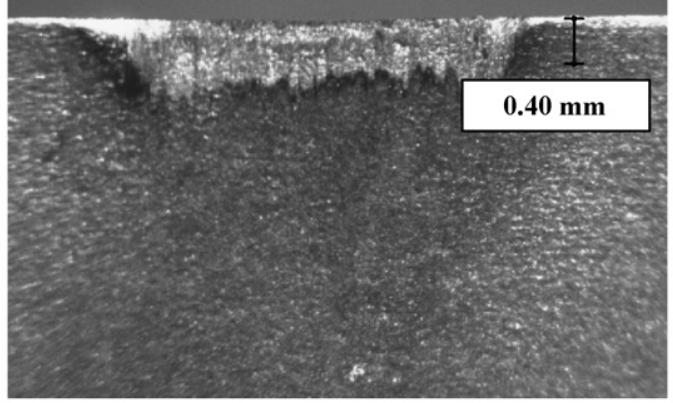

(b)

Flank wear vs cutting time $\left(\mathrm{M} 2+\mathrm{TiCN}\right.$ tool, rake angle $0^{\circ}$ and $10^{\circ}$ )

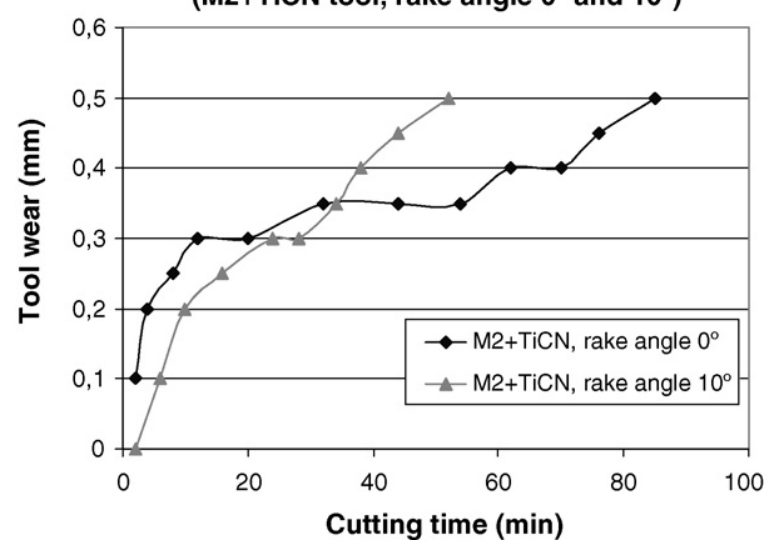

Fig. 10. $\mathrm{M} 2+50 \% \mathrm{TiCN}$ tool material. (a) Flank wear measured during the experimental study of wear evolution, cutting insert with rake angle equal to $0^{\circ}$. (b) Effect of rake angle in flank wear evolution.

over the cutting edge. It is possible to observe also the flank wear in the clearance surface in both cases.

As was observed in the case of M2 tools, the M2+50\% TiCN tools with robust geometry (rake angle $0^{\circ}$ ) presented improved resistance to chipping wear in the cutting edge related with increased tool life. This phenomenon is stronger in the case of reinforced material, due to the presence of brittle hard phase requiring a robust cutting geometry.

\subsection{Comparison with commercial M2 and effect of cutting speed}

The behaviour of new cermet was also compared with commercial HSS M2 inserts (rake angle $0^{\circ}$ ) in the same cutting conditions (cutting speed $30 \mathrm{~m} / \mathrm{min}$ and feed $0.1 \mathrm{~mm} / \mathrm{rev}$ ). The tool life of commercial M2 insert was $7 \mathrm{~min}$. The evolution of flank wear with cutting time is shown in Fig. 12 for M2 sintered in laboratory, com-
Tool wear vs cutting time $\left(\mathrm{M} 2+\mathrm{TiCN}\right.$ and $\mathrm{M} 2$ tools, rake angle $\left.0^{\circ}\right)$

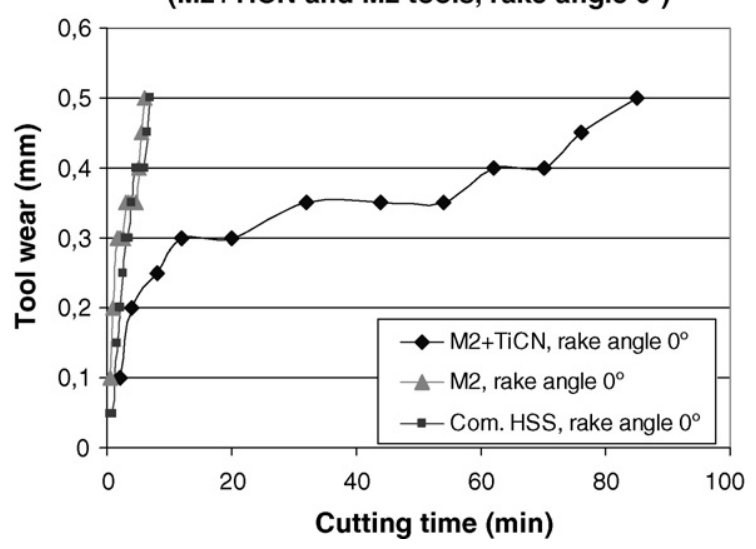

Fig. 12. Flank wear evolution, commercial HSS M2 tool, M2 and M2 $+50 \% \mathrm{TiCN}$, rake angle $0^{\circ}$, cutting speed $30 / \mathrm{min}$, feed $0.1 \mathrm{~mm} / \mathrm{rev}$.

Table 3

Tool life for M2 $+50 \%$ TiCN and commercial HSS inserts.

\begin{tabular}{lllll}
\hline M2+50\%TiCN insert & & & \multicolumn{2}{l}{ HSS commercial insert } \\
\cline { 5 - 5 } Vc $(\mathrm{m} / \mathrm{min})$ & $T(\mathrm{~min})$ & & Vc $(\mathrm{m} / \mathrm{min})$ & $T(\mathrm{~min})$ \\
\hline 30 & 85 & 30 & 7 \\
40 & 19 & 40 & 4 \\
50 & 9 & 50 & 2 \\
60 & 6 & 60 & 0.8 \\
\hline
\end{tabular}

mercial HSS and M2 +50\% TiCN. Similar behaviour of commercial HSS and laboratory M2 is observed, indicating reasonably quality of the manufacturing process.

The effect of cutting speed was analysed carrying out turning tests at 40,50 and $60 \mathrm{~m} / \mathrm{min}$ (feed was $0.1 \mathrm{~mm} / \mathrm{rev}$ ) with both commercial HSS and the cermet. The values of cutting speed were selected taking into consideration that the tests were carried out in dry conditions. This condition was a strong limitation for cutting speed, since HSS is normally used in cutting operations with coolant.

Cutting inserts with rake angle equal to $0^{\circ}$ were tested for the analysis of the influence of cutting speed. Table 3 summarizes the values of tool life obtained for the range of cutting speed tested. Fig. 13a and $b$ shows the flank wear evolution for both materials in the range $30-60 \mathrm{~m} / \mathrm{min}$ tested. It can be observed the strong dependence of wear evolution with cutting speed. Wear progressed much faster as the test velocity increased.
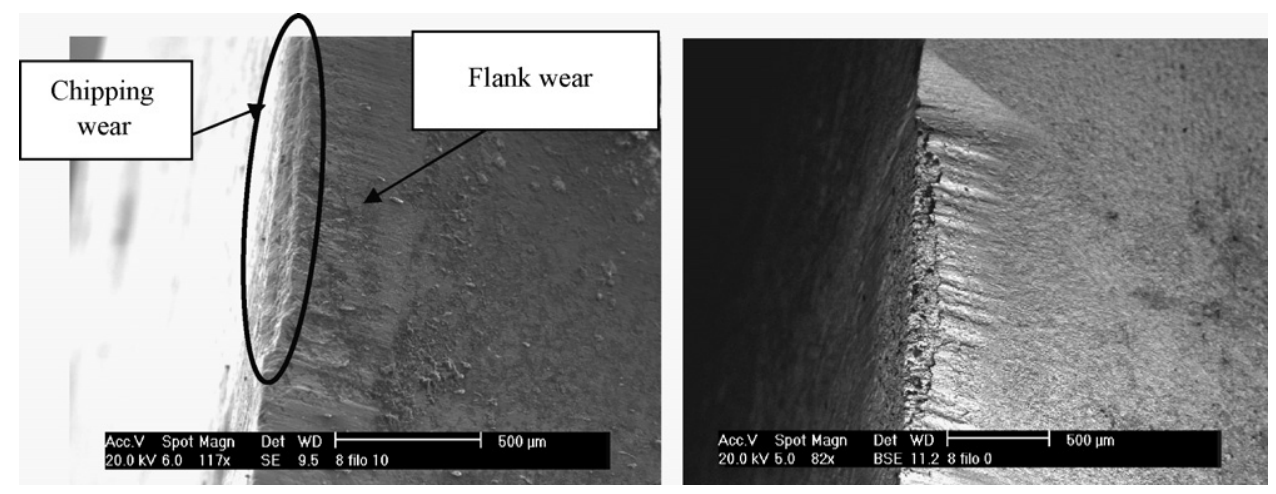

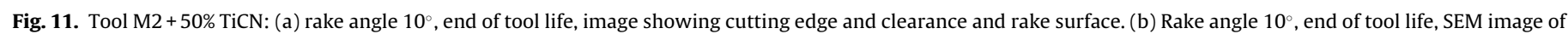
the cutting edge. 
Tool wear evol. for different cutting speeds (M2+50\% TiCN)

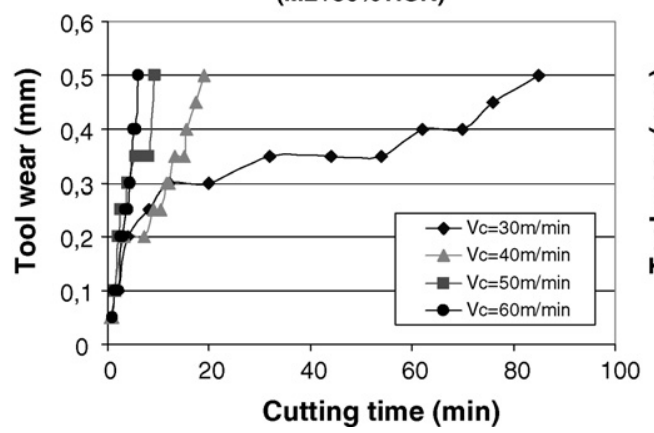

Tool wear evol. for different cutting speeds (Commercial HSS)

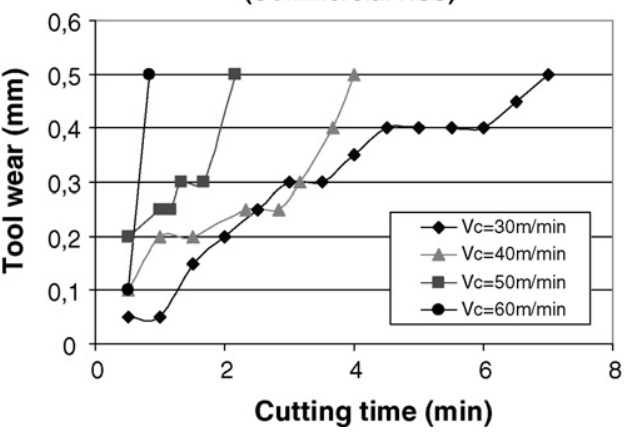

Fig. 13. Flank wear evolution for different cutting speeds (feed $0.1 \mathrm{~mm} / \mathrm{rev}$ and rake angle $0^{\circ}$ ): (a) $\mathrm{M} 2+50 \% \mathrm{TiCN}$ tool and (b) commercial $\mathrm{HSS}$ tool

\section{Conclusions}

Several conclusions can be obtained from the study presented in this paper. A new cutting material, the cermet $\mathrm{M} 2+50 \%$ TiCN was prepared by the conventional powder metallurgy (PM) route of mixing of starting powders, pressing and sintering. The same process was used to develop M2 inserts that were used as a reference material for comparison with the new material.

As a result of the study concerning heat treatments, the optimal conditions of treatment were selected: quenching in oil at $1200^{\circ} \mathrm{C}$ and double tempering at $560{ }^{\circ} \mathrm{C}$ for both the composite $\mathrm{M} 2+\mathrm{TiCN}$ and the reference material M2. The final hardness of the composite was 25\% higher than the as-sintered material, reaching values of 1550 HV30; the fracture toughness increases the $40 \%$ with respect to the as-sintered material, up to $14 \mathrm{MPa} \mathrm{m}^{1 / 2}$.

Orthogonal turning tests (at constant cutting speed and feed rate) were performed with both cutting materials $\mathrm{M} 2$ and $\mathrm{M} 2+50 \%$ TiCN. Two rake angles, $0^{\circ}$ and $10^{\circ}$ were tested.

Also commercial HSS inserts were tested and compared with cermet inserts. These tests were performed in the range $30-60 \mathrm{~m} / \mathrm{min}$ showing significant influence of cutting speed on tool wear evolution. The behaviour of commercial HSS was similar to that showed by M2 sintered at the laboratory. This fact was interpreted as a validation of the materials manufacturing process.

Although this preliminary work should be extended performing cutting tests in different conditions, the new material demonstrated its ability to be used in cutting inserts in the range of cutting speed $30-60 \mathrm{~m} / \mathrm{min}$, in dry conditions. The absence of coolant implies extreme conditions of temperature at the interface, thus the range of cutting speed tested was limited by dry condition of the tests. The new cermet showed improved wear resistance and increased tool life when compared with both the reference material M2 sintered at the laboratory and the commercial HSS inserts.

The main mechanisms of tool wear were flank wear and chipping at the cutting edge. The addition of hard phase diminished significantly the evolution of tool wear. Tool life was increased one order of magnitude in the case of the cermet when compared with the reference material M2 and the commercial HSS.

Future work will involve analysis of extended cutting conditions and different tool geometries. Rounded cutting edge or chamfered edge could prevent the chipping wear improving the wear resistance of the tools, even when the rake angle is positive.

\section{Acknowledgement}

The authors acknowledge financial support to the Ministry of Education and Science of Spain (Project DPI2005-08018).

\section{References}

Aigner, K., Lengauer, W., Ettmayer, P., 1997. Interactions in iron-based cermet systems. J. Alloys Compd. 262-263, 486-491.

Bellosi, A., Calzavarini, R., Faga, M.G., Monteverde, F., Zancolò, C., D’Enrico, G.E., 2003. Characterisation and application of titanium carbonitride cutting tools. J. Mater. Process. Technol. 143-144, 527-532.

Davis, J.A., 1995. Tool Materials: ASM Specialty Handbook, first ed. ASM.

Deo, D.M., Saxena, J.P., Basu, S., 1988. Some experiences on performance and behaviour of steel bonded cemented carbide, advances in hard materials production. In: Proceedings of Metal Powder Report Conference, London, 17, 1-10.

Deshpande, M.V., Saxena, J.P., Basu, S., 1992. Experience in development of a tough cemented carbide cutting tool material with iron based binder. In: Proceedings of Advances in Hard Materials Production Conference. MPR Publication, Bonn, 22, 1-13.

Deshpande, M.V., Saxena, J.P., Basu, S., Sebart, W., 1997. Tougher cemented carbide material with iron-rich binder for steel turning and form-grooving. Int. J. Refr. Met. Hard Mater. 15, 157-162.

Ettmayer, P., Kolaska, H., Lengauer, W., Dreyer, K., 1995. TiCN cermets-metallurgy and properties. Int. J. Refr. Met. Hard Mater. 13, 343-351.

Gómez, B., 2007. Desarrollo de nuevos materiales compuestos de matriz hierro basados en el sistema Fe-TiCN. Ph.D. Thesis. Universidad Carlos III de Madrid.

Gómez, B., Gordo, E., Torralba, J.M., 2006. Effect of milling time on the processing of Fe-TiCN composites. Mater. Sci. Eng. A 430, 59-63.

Gomez, B., Gordo, E., 2007. Fe-matrix composites: atmosphere effect during the sintering process. In: Proceedings of the International Powder Metallurgy Congress and Exhibition (PM2007). EPMA, UK, I, 269-274.

Gómez, B., Jiménez, A., Gordo, E., 2009. Oxidation and tribological behaviour of an Fe-based MMC reinforced with TiCN particles. Int. J. Refr. Met. Hard Mater. 27 (2), 360-366.

Gordo, E., Velasco, F., Antón, N., Torralba, J.M., 2000. Wear mechanisms in high speed steel reinforced with (NbC)p and (TaC)p MMCs. Wear 239, 251-259.

Gordo, E. Gomez, B., Ruiz-Navas, E. Torralba, J.M., 2008. Response to heat treatments of Fe-TiCN composites for wear applications. In: Proceedings of the Powder Metallurgy \& Particulate Materials World Congress. MPIF, USA, ISBN 0-9793488 9-7, 6, 120-130.

Hoyle, G., 1988. High Speed Steels. Butterworths.

Li, Y., Liu, N., Zhang, X., Rong, C., 2008. Effect of tWC content on the microstructure and mechanical properties of $(\mathrm{Ti}, \mathrm{W})(\mathrm{C}, \mathrm{N})$-Co cermets. Int. J. Refr. Met. Hard Mater. 26, 33-40.

Pastor, H., 1988. Titanium carbonitride based hard alloys for cutting tools. Mater Sci. Eng. A 105/106, 401-409.

Rahimi Dizaji, V., Rahmani, M., Faghihi Sani, M., Nemati, Z., Akbari, J. 2007. Microstructure and cutting performance investigation of $\mathrm{Ti}(\mathrm{C}, \mathrm{N})$-based cermets containing various types of secondary carbides. Int. J. Mach. Tools Manuf. 47 768-772.

Sandvik Coromant, Modern Metal Cutting, 2003.

Umanskii, A.P., 2001. Titanium carbonitride composite with iron-chromium binder. Powder Metall. Met. Ceram. 40 (11), 637-640.

Zhang, H., Yan, J., Zhang, X., Tang, S., 2006. Properties of titanium carbonitride matrix cermets. Int. J. Refr. Met. Hard Mater. 24, 236-239.

Zhang, H., Tang, S., Yan, J., Hu, X., 2007. Cutting performance of titanium carbonitride cermet tools. Int. J. Refr. Met. Hard Mater. 25, 440-444. 